\title{
Evolution of inbreeding: a gaze into five Italian beef cattle breeds history
}

Giacomo Rovelli ${ }^{1,2}$, Maria Gracia Luigi-Sierra ${ }^{2}$, Dailu Guan ${ }^{2,3}$, Fiorella Sbarra ${ }^{4}$, Andrea Quaglia ${ }^{4}$, Francesca

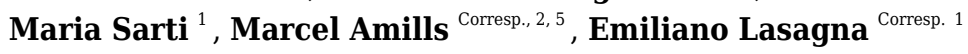

${ }^{1}$ Department of Agricultural, Food and Environmental Sciences (DSA3), University of Perugia, Perugia, Italy

Centre for Research in Agricultural Genomics (CRAG), CSIC-IRTA-UAB-UB, Universitat Autónoma de Barcelona, Bellaterra, Barcelona, Spain

3 Department of Animal Science, University of California, Davis, Davis, California, United States of America

4 National Association of Italian Beef-Cattle Breeders (ANABIC), San Martino in Colle, Perugia, Italy

5 Departament de Ciència Animal i dels Aliments, Universitat Autónoma de Barcelona, Bellaterra, Barcelona, Spain

Corresponding Authors: Marcel Amills, Emiliano Lasagna

Email address: marcel.amills@uab.cat, emiliano.lasagna@unipg.it

In the last decades, intensive selection programs have led to sustained increases of inbreeding in dairy cattle, a feature which might have adverse consequences on the viability and phenotypic performance of their offspring. The aim of this study was to determine the evolution of inbreeding of the five Italian beef cattle breeds (Marchigiana, Chianina, Romagnola, Maremmana, and Podolica) during a period of almost 20 years (2002-2019). The estimates of $\mathrm{Ho}, \mathrm{He}, F_{\text {hat2 }}$ and $F_{\text {ped }}$ averaged across years (2002-2019) in the studied breeds fluctuated between $0.340-0.401,0.348-0.392,-0.121-0.072$, and 0.000-0.068, respectively. Moreover, the annual rate of increase of the estimated inbreeding coefficients has been very low $\left(F_{\text {hat } 2}=0.01-0.02 \% ; F_{\text {ped }}=0.003-0.004 \%\right.$ ). The use of a high number of bulls combined with strategies implemented by the Association of Italian Beef Cattle Breeders (ANABIC) to minimize inbreeding might explain these results. Despite the fact that diversity and inbreeding have remained quite stable during the last two decades, we have detected a sustained decrease of the population effective size of these five breeds. Such result should be interpreted with caution due to the inherent difficulty of estimating $\mathrm{N}_{\mathrm{e}}$ from SNPs data in a reliable manner. 


\section{Evolution of inbreeding: a gaze into five Italian beef}

\section{2 cattle breeds history}

3

4 Giacomo Rovelli ${ }^{1,2}$, Maria Gracia Luigi-Sierra ${ }^{2}$, Dailu Guan $^{2,3}$, Fiorella Sbarra ${ }^{4}$, Andrea

5 Quaglia $^{4}$, Francesca Maria Sarti ${ }^{1}$, Marcel Amills ${ }^{2,5^{*+}}$, Emiliano Lasagna $^{1_{+}}$

$7{ }^{1}$ Department of Agricultural, Food and Environmental Sciences (DSA3), University of Perugia, 8 Perugia, Italy

$9{ }^{2}$ Centre for Research in Agricultural Genomics (CRAG), CSIC-IRTA-UAB-UB, Universitat

10 Autonòma de Barcelona, Bellaterra, Spain

$11{ }^{3}$ Department of Animal Science, University of California, Davis, California, United States of 12 America

$13{ }^{4}$ National Association of Italian Beef-Cattle Breeders (ANABIC), San Martino in Colle, Perugia, 14 Italy

$15{ }^{5}$ Departament de Ciència Animal i dels Aliments, Universitat Autònoma de Barcelona, Bellaterra, 16 Spain

18 Corresponding Authors:

19 Prof. Emiliano Lasagna

20 Borgo XX Giugno 74, Perugia, 06121, Italy

21 Email address: emiliano.lasagna@unipg.it 


\section{Prof. Marcel Amills}

24 Carrer de la Vall Moronta, Bellaterra de Cerdanyola del Vallés, Barcelona, 08193, Spain

25 Email address: marcel.amills@uab.cat

26

$27{ }^{+}$These authors contributed equally to the work.

28 


\section{Abstract}

30 In the last decades, intensive selection programs have led to sustained increases of inbreeding in

31 dairy cattle, a feature which might have adverse consequences on the viability and phenotypic

32 performance of their offspring. The aim of this study was to determine the evolution of

33 inbreeding of the five Italian beef cattle breeds (Marchigiana, Chianina, Romagnola,

34 Maremmana, and Podolica) during a period of almost 20 years (2002-2019). The estimates of

$35 \mathrm{Ho}, \mathrm{He}, F_{\text {hat } 2}$, and $F_{\text {ped }}$ averaged across years (2002-2019) in the studied breeds fluctuated

36 between $0.340-0.401,0.348-0.392,-0.121-0.072$, and $0.000-0.068$, respectively. Moreover, the

37 annual rate of increase of the estimated inbreeding coefficients has been very low $\left(F_{\text {hat } 2}=0.01-\right.$

$380.02 \% ; F_{\text {ped }}=0.003-0.004 \%$ ). The use of a high number of bulls combined with strategies

39 implemented by the Association of Italian Beef Cattle Breeders (ANABIC) to minimize

40 inbreeding might explain these results. Despite the fact that diversity and inbreeding have

41 remained quite stable during the last two decades, we have detected a sustained decrease of the

42 population effective size of these five breeds. Such result should be interpreted with caution due

43 to the inherent difficulty of estimating $\mathrm{N}_{\mathrm{e}}$ from SNPs data in a reliable manner.

\section{Keywords}

Bos taurus, genetic diversity, coancestry, effective population size, single nucleotide

47 polymorphism.

\section{Introduction}

50 Inbreeding is the main consequence of mating individuals that are related, through common

51 ancestry, to a degree that exceeds that of two individuals from the same population extracted at 
52 random (Kardos et al., 2016). Minimizing inbreeding is an aspect of paramount importance in

53 cattle breeding to avoid the phenotypic expression of detrimental alleles in the offspring

54 as well as to ensure the maintenance of genetic diversity (Howard et al., 2017). Inbred animals

55 display chromosome segments that are identical-by-descent (IBD) and generate long runs of

56 homozygosity (Kardos et al., 2016). Although inbreeding coefficients can be calculated from

57 pedigrees comprising several generations, in the recent years the advent of high throughput

58 genotyping techniques has made possible to estimate molecular inbreeding coefficients based on

59 the characterization of the genome-wide patterns of homozygosity. One key advantage of this

60 latter approach is that it captures ancient inbreeding accumulated in the base population and it is

61 less affected by parentage errors (Howard et al., 2017). However, some papers (Bjelland et al.,

62 2013; Pryce et al., 2014) have revealed the distortion caused by ancient contributions to

63 inbreeding dilutes up to a degree in which pedigree-based analyses and genomic analyses may

64 not differ that much.

65 Inbreeding is often reported in domestic animal populations as a measurement of one or several

66 coefficients of inbreeding at a particular time point. However, assessing the magnitude of

67 inbreeding on a continuous temporal scale is much more informative because it captures its

68 tendency and predicted behaviour. Between 1960 and 2000, inbreeding coefficients of US dairy

69 breeds, such as Ayrshire, Brown Swiss, Guernsey, Holstein, and Jersey, went from 0\% (base

70 population) to $4.5-6 \%$ in just four decades (Weigel, 2001). According to Weigel (2001), this

71 increase in inbreeding was not associated with effective population size and, more likely, it was

72 the result of the intensity of genetic selection as well as of the extensive use of a reduced number

73 of elite sires. Similarly, McParland et al. (2007) investigated the evolution of inbreeding in the

74 Charolais, Limousine, Hereford, Angus, and Simmental beef cattle breeds as well as in the 
75 Holstein-Friesian dairy cows raised in Ireland. They found that, between 1960 and 2004, overall

76 inbreeding increased from $0.10-0.25 \%$ to $0.5-2 \%$, and over the last decade (1994-2004) the

77 annual rate of increase in inbreeding was $0.06-0.13 \%$. These and other studies suggest that

78 inbreeding is accumulating rapidly in cattle breeds due to efficient genetic selection programs

79 and reproductive management (Weigel, 2001).

80 Genetic selection in Italian beef cattle is implemented by the National Association of Italian Beef

81 Cattle Breeders (ANABIC) and aimed to improve meat production, precocity, growth ability,

82 and muscle development (Sbarra, 2011). Three of the five main Italian beef cattle breeds,

83 Marchigiana (MAR), Chianina (CHI), and Romagnola (ROM) are highly specialised in beef

84 production, and the other two, Maremmana (MRM) and Podolica (POD), are considered as rustic

85 (Sarti et al., 2019). Current selection program, based on the traditional quantitative approach, has

86 achieved a remarkable improvement of growth, daily weight and muscularity gain (Sbarra,

87 2011). Moreover, cattle are somatically well-developed with a correct morphology and light

88 skeletal system (Rovelli et al., 2020a). However, the intensity of the selection in the five breeds

89 is lower in the rustic MRM and POD than in the three specialised ones; moreover, the two rustic

90 breeds register a low amount of young bulls / year in performance test (Fioretti et al., 2020). In

91 the current work, we aimed to characterize the historical evolution of inbreeding in five Italian

92 beef cattle breeds (CHI, MAR, ROM, MRM, and POD) in the period comprised between 2002

93 and 2019 by using both molecular and genealogical estimates of inbreeding coefficients. Our

94 goal was to test whether intensive selection performed in the last twenty years has resulted in a

95 significant increase of inbreeding levels in these five populations.

96

97 Materials \& Methods 
98 Cattle sampling and genotyping.

99 This work comprised 3,581 young bulls belonging to five of the main Italian beef cattle breeds:

100 CHI (909), MAR (879), ROM (904), MRM (334), and POD (555). The number of young bulls

101 and their year of birth are reported in Table S1. Samples were collected by staff from the

102 ANABIC at the genetic station of San Martino in Colle (Perugia, Italy) during 1985 - 2019.

103 Geographical distribution of these breeds in Italy and the pictures of representative individuals

104 from each breed can be found in Fig. 1.

105 During the performance test, blood samples were taken from the jugular veins of each bull.

106 These samples were collected in EDTA $\mathrm{K}_{3}$ coated vacuum tubes and stored at $-20^{\circ} \mathrm{C}$ (Rovelli et

107 al., 2020b). Genomic DNA was purified with the GenElute Blood Genomic DNA kit (Sigma

108 Aldrich, St. Louis, MO, USA). The purification method was previously described in Sarti et al.

109 (2019). Genomic DNA samples from the 3,581 bulls were genotyped with the GeneSeek

110 Genomic Profiler Bovine LDv4 33K chip (Illumina Inc., San Diego, CA, USA), which contains

11130,111 SNPs, and processed at the Agrotis laboratory (LGS, Cremona, Italy). Standard multi-

112 sample protocols and reagents were used according to the instructions of the manufacturer

113 (Khatkar et al., 2012).

114 The positions of single nucleotide polymorphisms (SNPs) were mapped using the ARS-

115 UCD_1.2 bovine genome assembly (Zorc et al., 2019). The PLINK software v1.9 (Chang et al.,

116 2015) was used to update the names and positions of SNP markers. The SNPs that did not match

117 the following criteria were removed before performing population diversity analyses: i) SNPs

118 with call rates less than 90\%, ii) SNPs with minor allele frequencies less than 5\%, iii) SNPs with

119 more than 1\% missing genotypes, and iv) SNPs displaying highly significant deviations $(P$-value

$120<10^{-3}$ ) from the Hardy-Weinberg equilibrium (Amaral et al., 2020). Another pruning step was 
121 performed to remove SNPs with high linkage disequilibrium (LD) using the command --indep 50

12252 (Manunza et al., 2016) of the PLINK v1.9 software (Chang et al., 2015) as recommended in a

123 previous publication (Howrigan et al., 2011). This second step is necessary because stretches of

124 SNPs with low MAF and genomic regions with many SNPs and strong LD often yield erroneous

125 estimates of the effective population size (Manunza et al., 2016). The results of these pruning

126 steps are shown in Table S2.

127

128 Data analysis.

129 Calculation of molecular inbreeding coefficient.

130 In the five studied breeds, inbreeding coefficient $F_{\text {hat } 2}$ was calculated for each bull with the

131 PLINK v1.9 software (Chang et al., 2015). The --ibc command of PLINK v1.9 (Chang et al.,

132 2015) was used to compute $F_{\text {hat } 2}$. The formula used to calculate $F_{\text {hat } 2}$ is as follows:

$$
F_{\text {hat } 2}=\frac{O_{\text {hom }}-E_{\text {hom }}}{1-E_{\text {hom }}}
$$

136 where $O_{\text {hom }}$ is the observed number of homozygotes and $E_{\text {hom }}$ is the expected number of

137 homozygotes.

138 The mean of the inbreeding coefficient was calculated per year (18 levels) for each one of the

139 five studied breeds. Animals born between 1985 and 2002 were merged into a single group

140 because the number of genotyped individuals born before 2002 is very scarce. The PROC REG

141 v14.1 tool (SAS Inst. Inc., Cary, NC) was used to estimate the annual rate of increase in $F_{\text {hat } 2}$ by

142 fitting a linear regression and considering the 2002-2019 period (Sall, 1981). The R software 
143 v4.0.3 (R Core Team, 2018) was used to perform a box plot to represent graphically the

144 inbreeding coefficient variation per year for each of the studied breeds.

145

146 Calculation of a pedigree - based inbreeding coefficient.

147 The Endog software v4.8 (Gutiérrez \& Goyache, 2005; Gutiérrez et al., 2009) was used to

148 calculate the pedigree inbreeding coefficient $\left(F_{p e d}\right)$, which is defined as the probability that an

149 individual has two IBD alleles (Ferenčaković et al., 2017). In addition to the default variables

150 proposed by the software, we also considered for $F_{p e d}$ estimation the average relatedness (AR)

151 coefficient. This parameter is defined as the probability of an allele, chosen randomly from the

152 entire population, to belong to a given animal, so AR can be understood as the representation of

153 the animal in the entire pedigree regardless of the knowledge of such pedigree (Gutiérrez et al.,

154 2009).

155 The depth and completeness of the pedigree are key when estimating inbreeding coefficients,

156 because an incomplete pedigree will lead to an underestimation of the mean inbreeding. We

157 calculated a pedigree completeness index (PCI) for each animal included in the pedigree using

158 the method developed by MacCluer et al. (1983) and implemented in Sargolzaei (2014). The

159 depth of the pedigree varied across breeds, since we have considered only the generations with

160 all known ancestors. For the rustic breeds (MRM and POD), the inbreeding coefficient $\left(F_{p e d}\right)$

161 was calculated considering four ancestral generations. In contrast, the MAR and CHI breeds

162 were represented by individuals from three ancestral generations while in ROM only

163 genealogical data from two generations were available. As previously said, the mean $F_{\text {ped }}$ per

164 year was computed for each of the five studied breeds, merging in one single group the animals

165 born between 1985 and 2002. The annual rate of increase in $F_{p e d}$ coefficient was estimated by 
166 fitting a linear regression using PROC REG v14.1 (SAS Inst. Inc., Cary, NC) through the time

167 period from 2002 to 2019 (Sall, 1981). This linear regression was plotted with the R software 168 v4.0.3 (R Core Team, 2018).

169

170 Estimation of genetic diversity and historic effective population size trends.

171 The Arlequin software v3.5.2.2 (Excoffier \& Lischer, 2010) was used to estimate within-

172 population diversity, by calculating observed $(\mathrm{Ho})$ and expected $(\mathrm{He})$ heterozygosities

173 subsequently corrected over the number of usable SNPs.

174 Historical trends in effective population size $\left(\mathrm{N}_{\mathrm{e}}\right)$ were estimated with the SNeP software

175 (Barbato et al., 2015) using default settings and a correction to adjust linkage disequilibrium

176 (LD) $r^{2}$ values for small sample sizes. The same index was also calculated through the individual

177 increase in inbreeding, using the software Endog v4.8 (Gutiérrez \& Goyache, 2005; Gutiérrez et

178 al., 2009).

179 The formula used to estimate $\mathrm{N}_{\mathrm{e}}$ from LD (Corbin et al., 2012), with SNeP software, was:

180

181

$$
N_{T(t)}=\frac{1}{\left(4 f\left(c_{t}\right)\right)}\left(\frac{1}{E\left[r_{a d j}^{2} \mid C_{t}\right]}-\alpha\right)
$$

183 Where $N_{T(t)}$ is the effective population size estimated $t$ generations ago in the past, $c_{t}$ is the

184 recombination rate $t$ generations ago in the past, $r^{2}$ adj is the linkage disequilibrium estimation 185 adjusted for sampling bias, and $\alpha$ is a constant.

186

\section{Results}


188 The average PCI from 2002 to 2019 ranged from 99.29 to $99.91 \%$ (MAR), from 99.17 to $99.89 \%$

189 (CHI), from 98.80 to $99.92 \%$ (ROM), from 99.01 to $99.87 \%$ (MRM), and from 99.02 to $99.86 \%$

190 (POD). The removal of genotyped animals with PCI less than 90\% resulted in the exclusion of

191 less than $1.5 \%$ of the sample, as most of the genotyped animals had PCI greater than $90 \%$. The

192 estimates of $\mathrm{Ho}, \mathrm{He}, F_{\text {hat } 2}$, and $F_{\text {ped }}$ averaged across years (2002-2019) in the studied breeds

193 fluctuated between $0.340-0.401,0.348-0.392,-0.121-0.072$, and $0.000-0.068$, respectively

194 (Tables 1 and 2). The $F_{\text {ped }}$ coefficients were higher in the rustic POD and MRM breeds, probably

195 because the depth of the pedigree (in our dataset) is higher than in the MAR, CHI, and ROM

196 breeds. Moreover, POD was the breed that displayed a highest $F_{\text {hat } 2}$ coefficient, followed by

197 ROM. The analysis of the evolution of $F_{\text {hat }}, F_{\text {ped }}$, and $H o$ in the five breeds (Figs. 2 and 3 )

198 evidenced that the observed heterozygosity, in the five studied populations, remained constant

199 throughout the years, with slightly higher values in the rustic breeds. With regard to $F_{\text {hat } 2}$ and

$200 F_{p e d}$, we observed some fluctuations across years that were particularly accentuated for $F_{\text {hat } 2}$

201 which showed a stable or increasing trend depending on the breed under consideration. In any

202 case, these yearly oscillations in the magnitude of inbreeding were not very important. The

203 MRM and POD breeds lacked data in one and three years, respectively. These missing values are

204 due to the fact that in Southern Italy, between 2004-2006, there was a "Bluetongue" epidemia

205 which caused a temporary cessation of the activities of the POD selection center. For the same

206 reason, MRM selection was temporarily suspended in 2013. The annual rates of increase in

207 inbreeding $\left(F_{\text {hat } 2}\right.$ and $\left.F_{\text {ped }}\right)$ are displayed in Figs. 4 and 5. It can be seen that in general $F_{\text {hat } 2}$

208 increases slightly but steadily in all five breeds, with averaged overall increasing rates of 0.17 -

$2090.34 \%$ between 2002-2019. In contrast, $F_{\text {ped }}$ remained quite stable across time with averaged

210 overall increasing rates of $-0.04-0.08 \%$. The effective population size $\left(\mathrm{N}_{\mathrm{e}}\right)$ estimated $\mathrm{t}$ 
211 generations ago (from 13 to 235 ) is shown in Fig. 6. It is apparent that $\mathrm{N}_{\mathrm{e}}$ decreases very

212 markedly across generations. Thirteen generations ago, $\mathrm{N}_{\mathrm{e}}$ was lower than 300 for most breeds

213 with the only exception of POD cattle $\left(\mathrm{N}_{\mathrm{e}}=498\right)$. In contrast, 235 generations ago $\mathrm{N}_{\mathrm{e}}$ oscillated

214 between 1887-3257, which is 7.48 times larger than current values.

215

216 Discussion

217 In this study, we have evaluated the variation of inbreeding and diversity parameters in five

218 Italian beef cattle breeds across a window of approximately 20 years. We did not measure $F_{\text {roh }}$

219 because the number of SNPs was too small (21,000-23,000 valid SNPs) to map runs of

220 homozygosity in a reliable manner. Importantly, in our study the base generation of each breed

221 was composed of animals born before 2002. We did so because there was a very small number of

222 bulls representing each one of the years comprised between 1985 and 2002, so they were merged

223 together in a single group. We have observed that the averaged (across years) coefficients of

224 inbreeding $F_{h a t 2}$ and $F_{p e d}$ in the five Italian breeds are generally lower than 0.07 (Table 2, Figs. 2,

2253,4 , and 5), while homozygosity was approximately $0.64-0.70$ (data not shown). The $F_{\text {hat }}$

226 coefficient is closely related to $F_{i s}$ and can be interpreted (also in the case of $F_{\text {ped }}$ computed $F_{i s}$ )

227 in breeding policy terms: in fact, positive and high values mean that mating between close

228 relative are not - or cannot be - avoided. In smaller populations, like those at issue, breeders are

229 implementing a more rigorous breeding policy to limit inbreeding within the herd. The MRM

230 and POD breeds displayed the largest $F_{\text {ped }}$ coefficients but this was expected because the depth

231 of the pedigree, in our study, is larger than for CHI, MAR, or ROM. Another reason explaining

232 the larger $F_{\text {ped }}$ (and lower AR) observed in the rustic breeds (MRM and POD) relies on the fact

233 that in these breeds artificial insemination (AI) is little spread. Bulls, especially in the past, were 
234 the offspring of animals born in the same farm. Furthermore, farms always remained quite

235 isolated and poorly genetically connected to each other, at least until the foundation of test

236 stations (Moioli et al., 2004). On the other hand, in the specialized breeds (MAR, CHI, and

$237 \mathrm{ROM}$ ), the implementation of $\mathrm{AI}$ involved the use of unrelated lines thus avoiding inbreeding to

238 a great extent (higher AR). We have observed slight discrepancies between $F_{\text {hat } 2}$ and $F_{\text {ped }}$ values

239 displayed in Table 2, but this outcome is probably explained by the fact that these two

240 coefficients have different properties (Alemu et al., 2021). Indeed, $F_{p e d}$ indicates the probability

241 that two homologous alleles in an individual are identical by descent, as defined by Malécot

242 (1948), and it ranges from 0 to 1 . In contrast, $F_{\text {hat } 2}$ is very similar to the method-of-moments $F$

243 coefficient measured with the --het command of PLINK v1.9 (Purcell et al., 2007) which

244 estimates the reduction of heterozygosity (or the excess of homozygosity) associated with

245 inbreeding (Alemu et al., 2021). In consequence, $F_{\text {hat } 2}$ can take negative values (Alemu et al.,

246 2021). Despite these conceptual differences, comparison of $F_{p e d}$ and $F_{\text {hom }}$ (similar to $F_{\text {hat } 2}$ )

247 coefficients calculated in a pedigree of 245 Holstein cattle with whole-genome sequence data

248 showed a good agreement between both parameters (Alemu et al., 2021). In our study, both

249 coefficients indicate that none of the Italian breeds under study is significantly inbred.

250 We have also observed a lack of relationship between population size and the magnitude of

251 inbreeding coefficients (Table 2, Figs. $2,3,4$, and 5). For instance, $\operatorname{MRM}\left(F_{\text {hat } 2}=0.014, F_{p e d}=\right.$

$2520.061)$ and $\operatorname{ROM}\left(F_{\text {hat } 2}=0.023, F_{\text {ped }}=0.023\right)$ have population sizes of approximately $11,000-$

25312,000 individuals, while MAR has a census almost five times larger but fairly comparable

254 levels of inbreeding $\left(F_{\text {hat } 2}=0.012, F_{\text {ped }}=0.018\right)$. The amount of inbreeding is mostly determined

255 by the demographic history of populations rather than by their current size. In local breeds

256 undergoing strong demographic reductions, genetic drift can be quite intense thus increasing 
257 homozygosity and the occurrence of matings between related individuals. For instance,

258 Chillingham cattle (a breed that lives in Northumberland earldom, England) are currently

259 represented by a herd of 50 males and 50 females, which has remained reproductively closed in

260 the last 300-350 years (Visscher et al., 2001). This herd was formed by five bulls and eight cows

261 in 1947, and the average number of males and females per generation has been three and 15 ,

262 respectively (Visscher et al., 2001). Calculation of $F_{i s}$ inbreeding coefficient in Chillingham

263 cattle yielded a value of 0.92 , which is extremely high (Williams et al., 2016). In strong contrast,

264 the population sizes of the five Italian breeds analyzed in the current work have remained

265 relatively stable in the last 10 years and, to the best of our knowledge no genetic bottlenecks

266 have been recorded. Interestingly, Weigel (2001) also observed a lack of correlation between the

267 magnitude of inbreeding and the population size of five major US dairy breeds (Ayrshire, Brown

268 Swiss, Guernsey, Holstein, and Jersey). Noteworthy, breeds with small (Jersey) and large

269 (Holstein) population sizes had comparable levels of inbreeding, probably because in both

270 populations the intensity of selection was considerably high (Weigel, 2001).

271 We have compared the $F_{\text {hat } 2}$ values measured in MAR, ROM, CHI, MRM, and POD breeds with

$272 F_{\text {hom }}$ values reported by Mastrangelo et al. (2018) in the same breeds. As previously explained,

273 these two inbreeding coefficients, generated with the PLINK v1.9 software (Purcell et al., 2007)

274 are quite comparable and both measure the reduction in heterozygosity associated with

275 inbreeding. We observed that in general the $F_{\text {hom }}$ coefficients measured by Mastrangelo et al.

276 (2018) in the same five breeds analyzed by us are higher (in the $0.066-0.118$ range) than the $F_{\text {hat } 2}$

277 coefficients estimated in the current work. Biscarini et al. (2020) reported an $F_{p e d}$ coefficient for

278 the MRM breed of 0.049 , which is similar to the result obtained by us (Table 2). In another

279 study, Moioli et al. (2004) described Wright $F_{i s}$ coefficients of 0.106 and 0.138 in the POD and 
280 MRM breeds, and Santana et al. (2012) measured an $F_{p e d}=0.013$ in Brazilian MAR cattle. One

281 potential reason for the discrepancy between our results and those of Mastrangelo et al. (2018) is

282 that we have estimated allele and genotype frequencies with much more accuracy because our

283 sample size is much larger i.e., Mastrangelo et al. (2018) used samples sizes of 21-24 animals

284 while we have used sample sizes of 334-909 animals. This can be particularly important when

285 measuring the excess of homozygosity in SNP markers with low or very low minimum allele 286 frequencies.

287 Despite the fact that we have detected fluctuations in the magnitudes of $F_{\text {hat } 2}$ and $F_{p e d}$ during the

288 last 20 years, these oscillations were not very important (Figs. 2 and 3). Changes in

289 homozygosity and inbreeding coefficients across time might be partly explained by the fact that

290 the number of breeders, and particularly sires, is not constant across years. We have also

291 observed a slight increase of $F_{\text {hat } 2}$ in the five breeds during 2002-2020, particularly in MRM,

292 POD, and CHI, increasing 0.01-0.02\% per year, while $F_{\text {ped }}$ remained quite stable, with an annual

293 rate of increase of 0.003-0.004\% per year (Figs. 4 and 5). McParland et al. (2007) measured the

294 evolution of the inbreeding in five Irish cattle and observed that in the 1994-2004 period $F_{\text {ped }}$

295 remained constant or decreased in Angus, Charolais, and Limousine populations, while in

296 Hereford, Holstein-Friesian, and Simmental a yearly increase of $F_{\text {ped }}$ (between 0.06-0.13\%) was

297 detected. In another study, Weigel (2001) also reported increases of $F_{p e d}$ of $0.10-0.15 \%$ per year.

298 In the case of the five Italian breeds under study, such increases are much more modest, because

299 the ANABIC genetic program is designed to minimize inbreeding. A high number of bulls is

300 used in natural reproduction, rather than a few elite sires, and each one of them is mated with few

301 cows, because this approach ensures an offspring with low inbreeding coefficients. The matings 
302 are programmed and designed to minimize inbreeding, using the less related pairs of breeders

303 and allowing a maximum inbreeding increment of 5\% in each mating (Sbarra et al., 2011).

304 By using the SNeP (Barbato et al., 2015) and Endog v4.8 (Gutiérrez \& Goyache, 2005; Gutiérrez

305 et al., 2009) tools, we have detected a sustained and marked decline in the effective population

306 size of the five breeds under investigation. Mastrangelo et al. (2018) reported a very similar

307 tendency in the same five populations. Effective population size is a complex parameter defining

308 the size of a Wright-Fisher ideal population generating the same rate of inbreeding and variance

309 of gene frequencies detected in the real population under investigation (Crow \& Kimura, 1970).

310 In principle, selection and reproductive management, particularly in AI schemes in which a

311 reduced number of bulls mate with a large number of cows, are expected to reduce $\mathrm{N}_{\mathrm{e}}$. Although,

$312 \mathrm{~N}_{\mathrm{e}}$ cannot be equated to a coefficient of inbreeding or diversity because it depends on many

313 variables (Wang et al., 2016), it is remarkable that this strong $\mathrm{N}_{\mathrm{e}}$ decline (Fig. 6) was not

314 accompanied by a substantial reduction in $\mathrm{Ho}$ or $\mathrm{He}$ in the last 20 years (Figs. 2 and 3). Increased

315 variance in family size associated with the upward trend to use a reduced number of elite sires as

316 breeders could be one of the major reasons for this progressive decline of $\mathrm{N}_{\mathrm{e}}$. However, it should

317 be also noticed that estimates of $\mathrm{N}_{\mathrm{e}}$ historical trajectories with the $\mathrm{SNeP}$ tool (Barbato et al.,

318 2015) are sometimes unreliable, particularly in the most recent and oldest generations (Corbin et

319 al., 2012). Besides, $\mathrm{N}_{\mathrm{e}}$ estimates are strongly affected by data manipulation factors (e.g., choice

320 of the minimum allele frequency threshold) employed in the analysis (Corbin et al., 2012;

321 Barbato et al., 2015) and one of the main tenets of the coalescent is that no SNP can be reliably

322 sampled after $4 \mathrm{~N}_{\mathrm{e}}$ generations in the past. So, our estimates of $\mathrm{N}_{\mathrm{e}}$ historical trajectories should be

323 interpreted with caution. 


\section{Conclusions}

326 The low level of inbreeding found in this study confirms the success of the Italian beef cattle

327 selection program carried out by ANABIC, which aimed to minimize inbreeding. We have

328 observed that the annual rate of increase of inbreeding in the five Italian cattle under study are

329 lower than what has been reported in several dairy breeds from the United States of America and

330 Ireland, probably because of factors related with reproductive management (high number of

331 breeding bulls, matings programmed to minimize inbreeding, etc.). We have also detected a

332 strong decrease of the effective size that is not accompanied by marked reductions of diversity or

333 substantially increased inbreeding. These $\mathrm{N}_{\mathrm{e}}$ estimates should be interpreted with caution due to

334 the inherent difficulty of measuring this complex parameter in a reliable manner.

336 Acknowledgements

337 The authors wish to thank the ANABIC (S. Martino in Colle, Perugia, Italy) for their cooperation

338 in this study, selecting and providing SNPs data and phenotypic information of Italian beef cattle

339 breeds. The authors also wish to thank the editor and the three referees for their valuable

340 comments on the manuscript and their constructive suggestions.

342 Additional Information and Declarations

\section{Funding.}

344 This work was supported by the projects: "Italian Biodiversity Environment Efficiency

345 Fitness"- I-BEEF 1 and 2 - 2014-2020 and 2020-2023. PSRN: Support for the conservation,

346 use and sustainable development of genetic resources in agriculture. Sub-measure 10.2. 


\section{Competing Interests.}

349 The authors declare that they have no competing interests.

351 Author Contributions.

352 Giacomo Rovelli performed population genetics analyses, prepared figures and tables, authored

353 and reviewed drafts of the paper, and approved the final draft.

354 Maria Gracia Luigi-Sierra performed population genetics analyses, reviewed drafts of the 355 paper, and approved the final draft.

356 Dailu Guan performed population genetics analyses, and approved the final draft of the paper.

357 Fiorella Sbarra and Andrea Quaglia, furnished the phenotypic raw data and pedigree files of

358 all the studied sample, reviewed drafts of the paper, and approved the final draft.

359 Francesca Maria Sarti reviewed drafts of the paper, and approved the final draft.

360 Marcel Amills and Emiliano Lasagna conceived the data analysis, authored and reviewed

361 drafts of the paper, and approved the final draft.

362

363 Animal Ethics.

364 The data were collected in accordance to the FAO guidelines for the characterization of animal

365 genetic resources. Animal management, animal husbandry and trait recording followed the

366 criteria for the assessment of animal welfare as identified and defined in by the Welfare Quality

367 Project (Vapnek \& Chapman, 2011; FAO, 2012).

368

369 Data Availability. 
370 All the data supporting the results of this article are presented within the article or in the

371 Supplemental Files. The raw genotypic and pedigree data are stored in the on-line repository

372 https://figshare.com/and it is available at DOI https://doi.org/10.6084/m9.figshare.14625864.v1.

373

374 References

375 Alemu SW, Kadri NK, Harland C, Faux P, Charlier C, Caballero A, Druet T. 2021. An

376 evaluation of inbreeding measures using a whole-genome sequenced cattle pedigree. Heredity

377 126(3):410-423. DOI: https://doi.org/10.1038/s41437-020-00383-9.

378 Amaral AJ, Pavão AL, Gama LT. 2020. Genomic tools for the conservation and genetic

379 improvement of a highly fragmented breed-The Ramo Grande cattle from the Azores. Animals

380 10(6):1089. DOI: https://doi.org/10.3390/ani10061089.

381 Barbato M, Orozco-terWengel P, Tapio M, Bruford MW. 2015. SNeP: a tool to estimate trends

382 in recent effective population size trajectories using genome-wide SNP data. Frontiers in

383 Genetics 6:109. DOI: https://doi.org/10.3389/fgene.2015.00109.

384 Biscarini F, Mastrangelo S, Catillo G, Senczuk G, Ciampolini R. 2020. Insights into Genetic

385 Diversity, Runs of Homozygosity and Heterozygosity-Rich Regions in Maremmana Semi-Feral

386 Cattle Using Pedigree and Genomic Data. Animals 10(12):2285. DOI:

387 https://doi.org/10.3390/ani10122285.

388 Bjelland DW, Weigel KA, Vukasinovic N, Nkrumah JD. 2013. Evaluation of inbreeding

389 depression in Holstein cattle using whole-genome SNP markers and alternative measures of

390 genomic inbreeding. Journal of Dairy Science 96(7):4697-4706. DOI:

391 https://doi.org/10.3168/jds.2012-6435. 
392 Chang CC, Chow CC, Tellier LC, Vattikuti S, Purcell SM, Lee JJ. 2015. Second-generation

393 PLINK: rising to the challenge of larger and richer datasets. Gigascience 4(1):s13742-015. DOI:

394 https://doi.org/10.1186/s13742-015-0047-8.

395 Corbin LJ, Liu AYH, Bishop SC, Woolliams JA. 2012. Estimation of historical effective

396 population size using linkage disequilibria with marker data. Journal of Animal Breeding and

397 Genetics 129(4):257-70. DOI: https://doi.org/10.1111/j.1439-0388.2012.01003.x.

398 Crow JF, Kimura M. 1970. An introduction to population genetics theory. An introduction to

399 population genetics theory. CABI: Cab direct press.

400 Excoffier L, Lischer HEL. 2010. Arlequin suite ver 3.5: a new series of programs to perform

401 population genetics analyses under Linux and Windows. Molecular Ecology Resources 10:564-

402 7. DOI: https://doi.org/10.1111/j.1755-0998.2010.02847.x.

403 Ferenčaković M, Sölkner J, Kapš M, Curik I. 2017. Genome-wide mapping and estimation of

404 inbreeding depression of semen quality traits in a cattle population. Journal of Dairy Science

405 100(6):4721-4730. DOI: https://doi.org/10.3168/jds.2016-12164.

406 Fioretti M, Negrini R, Biffani S, Quaglia A, Valentini A, Nardone A. 2020. Demographic

407 structure and population dynamics of Maremmana cattle local breed after 35 years of traditional

408 selection. Livestock Science 232:103903. DOI: https://doi.org/10.1016/j.livsci.2019.103903.

409 Food and Agriculture Organization of the United Nations (FAO). Phenotypic characterization of

410 animal genetic resources. Rome: 2012.

411 Gutiérrez JP, Goyache F. 2005. A note on ENDOG: a computer program for Analysis pedigree

412 information. Journal of Animal Breeding and Genetics 122:172-176. DOI:

413 https://doi.org/10.1111/j.1439-0388.2005.00512.x. 
414 Gutiérrez JP, Goyache F, Cervantes I. 2009. User's Guide-ENDOG v 4.6 a Computer Program

415 for Monitoring Genetic Variability of Populations Using Pedigree Information. Juan Pablo

416 Gutiérrez García press.

417 Howard JT, Pryce JE, Baes C, Maltecca C. 2017. Invited review: Inbreeding in the genomics era:

418 Inbreeding, inbreeding depression, and management of genomic variability. Journal of Dairy

419 Science 100(8):6009-6024. DOI: https://doi.org/10.3168/jds.2017-12787.

420 Howrigan D, Simonson M, Keller M. 2011. Detecting autozygosity through runs of

421 homozygosity: a comparison of three autozygosity detection algorithms. BMC Genomics 12:460.

422 DOI: https://doi.org/10.1186/1471-2164-12-460.

423 Kardos M, Taylor HR, Ellegren H, Luikart G, Allendorf FW. 2016. Genomics advances the

424 study of inbreeding depression in the wild. Evolutionary Applications 9(10):1205-1218. DOI:

425 https://doi.org/10.1111/eva.12414.

426 Khatkar MS, Moser G, Hayes BJ, Raadsma HW. 2012. Strategies and utility of imputed SNP

427 genotypes for genomic analysis in dairy cattle. BMC Genomics 13(1):538. DOI:

428 https://doi.org/10.1186/1471-2164-13-538.

429 MacCluer JW, Boyce AJ, Dyke B, Weitkamp LR, Pfenning DW, Parsons CJ. 1983. Inbreeding

430 and pedigree structure in Standardbred horses. Journal of Heredity 74(6):394-399. DOI:

431 https://doi.org/10.1093/oxfordjournals.jhered.a109824.

432 Malécot G. 1948. Mathematics of heredity. Mathematics of heredity press.

433 Manunza A, Noce A, Serradilla JM, Goyache F, Martínez A, Capote J, Delgado JV, Jordana J,

434 Muñoz E, Molina A, Landi V, Pons A, Balteanu V, Traoré A, Vidilla M, Sanchez-Rodruguez M,

435 Sànchez A, Cardoso TF, Amills M. 2016. A genome-wide perspective about the diversity and 
436 demographic history of seven Spanish goat breeds. Genetic Selection Evolution 48(1):1-9. DOI:

437 https://doi.org/10.1186/s12711-016-0229-6.

438 Mastrangelo S, Ciani E, Marsan PA, Bagnato A, Battaglini L, Bozzi R, Carta A, Catillo G,

439 Cassandro M, Casu S, Ciampolini R, Crepaldi P, D’Andrea M, Di Gerlando R, Fontanesi L,

440 Longeri M, Macciotta NP, Mantovani R, Marletta D, Matassino D, Mele M, Pagnacco G,

441 Pieramati C, Portolano B, Sarti FM, Tolone M, Pilla, F. 2018. Conservation status and historical

442 relatedness of Italian cattle breeds. Genetics Selection Evolution 50(1):1-16. DOI:

443 https://doi.org/10.1186/s12711-018-0406-x.

444 Mc Parland S, Kearney JF, Rath M, Berry DP. 2007. Inbreeding trends and pedigree analysis of 445 Irish dairy and beef cattle populations. Journal of Animal Science 85(2):322-331. DOI:

446 https://doi.org/10.2527/jas.2006-367.

447 Moioli B, Napolitano F, Catillo G. 2004. Genetic diversity between Piedmontese, Maremmana, 448 and Podolica cattle breeds. Journal of Heredity 95(3):250-256. DOI:

449 https://doi.org/10.1093/jhered/esh032.

450 Pryce JE, Haile-Mariam M, Goddard ME, Hayes BJ. 2014. Identification of genomic regions 451 associated with inbreeding depression in Holstein and Jersey dairy cattle. Genetics Selection 452 Evolution 46(1):1-14. DOI: https://doi.org/10.1186/s12711-014-0071-7.

453 Purcell S, Neale B, Todd-Brown K, Thomas L, Ferreira MA, Bender D, Maller J, Sklar P, De 454 Bakker PIW, Daly MJ, Sham, P. C. 2007. PLINK: a tool set for whole-genome association and 455 population-based linkage analyses. The American Journal of Human Genetics 81(3):559-575. 456 DOI: https://doi.org/10.1086/519795. 
457 R Core Team. 2018. R: A language and environment for statistical computing. R Foundation for

458 Statistical Computing, Vienna, Austria. Available at https://www.r-project.org (accessed April $\left.45917^{\text {th }} 2021\right)$.

460 Rovelli G, Ceccobelli S, Perini F, Demir E, Mastrangelo S, Conte G, Abeni F, Marletta D,

461 Ciampolini R, Cassandro M, Bernabucci U, Lasagna, E. 2020a. The genetics of phenotypic

462 plasticity in livestock in the era of climate change: a review. Italian Journal of Animal Science

463 19(1):997-1014. DOI: https://doi.org/10.1080/1828051X.2020.1809540.

464 Rovelli G, Ceccobelli S, Perini F, Sbarra F, Quaglia A, Sarti FM, Lasagna E. 2020b. Genome 465 analysis in five Italian beef cattle breeds. Acta Fytotechnica et Zootechnica 23(4):112-115. DOI:

466 https://doi.org/10.15414/afz.2020.23.mi-fpap.112-115.

467 Sall J. SAS regression applications. SAS Institute, Cary, NC (EUA), 1981.

468 Santana Jr ML, Oliveira PS, Eler JP, Gutiérrez JP, Ferraz JBS. 2012. Pedigree analysis and 469 inbreeding depression on growth traits in Brazilian Marchigiana and Bonsmara breeds. Journal 470 of Animal Science 90(1):99-108. DOI: https://doi.org/10.2527/jas.2011-4079.

471 Sargolzaei M. SNP1101 User's Guide. Version 1. HiggsGene Solutions Inc., Guelph, Ontario, 472 Canada, 2014.

473 Sarti FM, Ceccobelli S, Lasagna E, Di Lorenzo P, Sbarra F, Pieramati C, Giontella A, Panella F. 474 2019. Influence a single nucleotide polymorphisms in some candidate genes related to the 475 performance traits in Italian beef cattle breeds. Livestock Science. 230:103834. DOI:

476 https://doi.org/10.1016/j.livsci.2019.103834.

477 Sbarra F. 2011. Genetics of autochthonous Italian beef cattle breeds. PhD Thesis, University of

478 Padua (Italy). Available at http://paduaresearch.cab.unipd.it (accessed April 26 $6^{\text {th }}$ 2021). 
479 Vapnek J, Chapman M. Legislative and regulatory options for animal welfare. Rome: Food and 480 Agriculture Organization of the United Nations (FAO); 2011.

481 Visscher PM, Smith D, Hall SJ, Williams JL. 2001. A viable herd of genetically uniform cattle. 482 Nature 409(6818):303-303. DOI: https://doi.org/10.1038/35053160.

483 Wang J, Santiago E, Caballero A. 2016. Prediction and estimation of effective population size. 484 Heredity 117(4):193-206. DOI: https://doi.org/10.1038/hdy.2016.43.

485 Weigel KA. 2001. Controlling inbreeding in modern breeding programs. Journal of Dairy 486 Science 84:E177-E184. DOI: https://doi.org/10.3168/jds.S0022-0302(01)70213-5.

487 Williams JL, Hall SJ, Del Corvo M, Ballingall KT, Colli L, Marsan PA, Biscarini F. 2016. 488 Inbreeding and purging at the genomic Level: the Chillingham cattle reveal extensive, 489 non-random SNP heterozygosity. Animal Genetics 47(1):19-27. DOI:

490 https://doi.org/10.1111/age.12376.

491 Zorc M, Ogorevc J, Dovc P. 2019. The new bovine reference genome assembly provides new 492 insight into genomic organization of the bovine major histocompatibility complex. Journal of 493 Central European Agriculture 20(4):1111-1115. DOI:

494 https://doi.org/10.5513/JCEA01/20.4.2679. 
495 Legends to figures

496

497 Figure 1. Geographical spread of the studied breeds in the different Italian regions (Italy map 498 taken from http://www.d-maps.com and adapted for illustrative purpose only).

Figure 2. Molecular $\left(F_{\text {hat } 2}\right)$ and pedigree $\left(F_{p e d}\right)$ inbreeding coefficients and observed

501

502

503

504

505 are the standard deviation. The base generation, represented as 1985-2002, is composed by Figure 3. Molecular $\left(F_{\text {hat } 2}\right)$ and pedigree $\left(F_{p e d}\right)$ inbreeding coefficients and observed heterozygosity of the rustic breeds (Maremmana and Podolica) measured in a period of almost 20 years (2002-2019). Ho: observed heterozygosity; $F_{\text {hat } 2}$ : molecular inbreeding coefficient; $F_{\text {ped }}$ : pedigree-based inbreeding. The dots represent the mean value and the whiskers

514 from few bulls were available before 2002). 
516 Figure 4. Overall percentual increase of $\boldsymbol{F}_{\text {hat } 2}$ and $\boldsymbol{F}_{p e d}$ for the specialised breeds

517 (Marchigiana, Chianina, and Romagnola).$F_{\text {hat } 2}$ : molecular inbreeding coefficient; $F_{\text {ped }}$ :

518 pedigree-based inbreeding. The red line represents the regression of the coefficients over time

519 expressed in years. The numbers next to the figure correspond to the overall increase of

520 inbreeding across all analyzed years.

522 Figure 5. Overall percentual increase of $\boldsymbol{F}_{\text {hat } 2}$ and $\boldsymbol{F}_{\text {ped }}$ for the rustic breeds (Maremmana

523 and Podolica). $F_{\text {hat } 2}:$ molecular inbreeding coefficient; $F_{\text {ped }}$ : pedigree-based inbreeding. The red

524 line represents the regression of the coefficients over time expressed in years. The numbers next 525 to the figure correspond to the overall increase of inbreeding across all analyzed years.

527 Figure 6. Effective population size $\left(\mathbf{N}_{\mathrm{e}}\right)$ across generation for each Italian beef cattle breed.

529 Supplemental files legends

530

531 Supplemental Table S1: Distribution of the number of young bulls per year and breed. 532

533 Supplemental Table S2: Number of autosomal SNPs and animals before (Pre) and after 534 (Post) SNPs sample filtering per breed. 


\section{Figure 1}

Geographical spread of the studied breeds in the different Italian regions (Italy map taken from https://www.d-maps.com/carte.php?num_car=14531\&lang=it and adapted for illustrative purpose only). Photo credit: National Association of Italian Beef Cattle B

(Italy map taken from http://www.d-maps.com and adapted for illustrative purpose only)

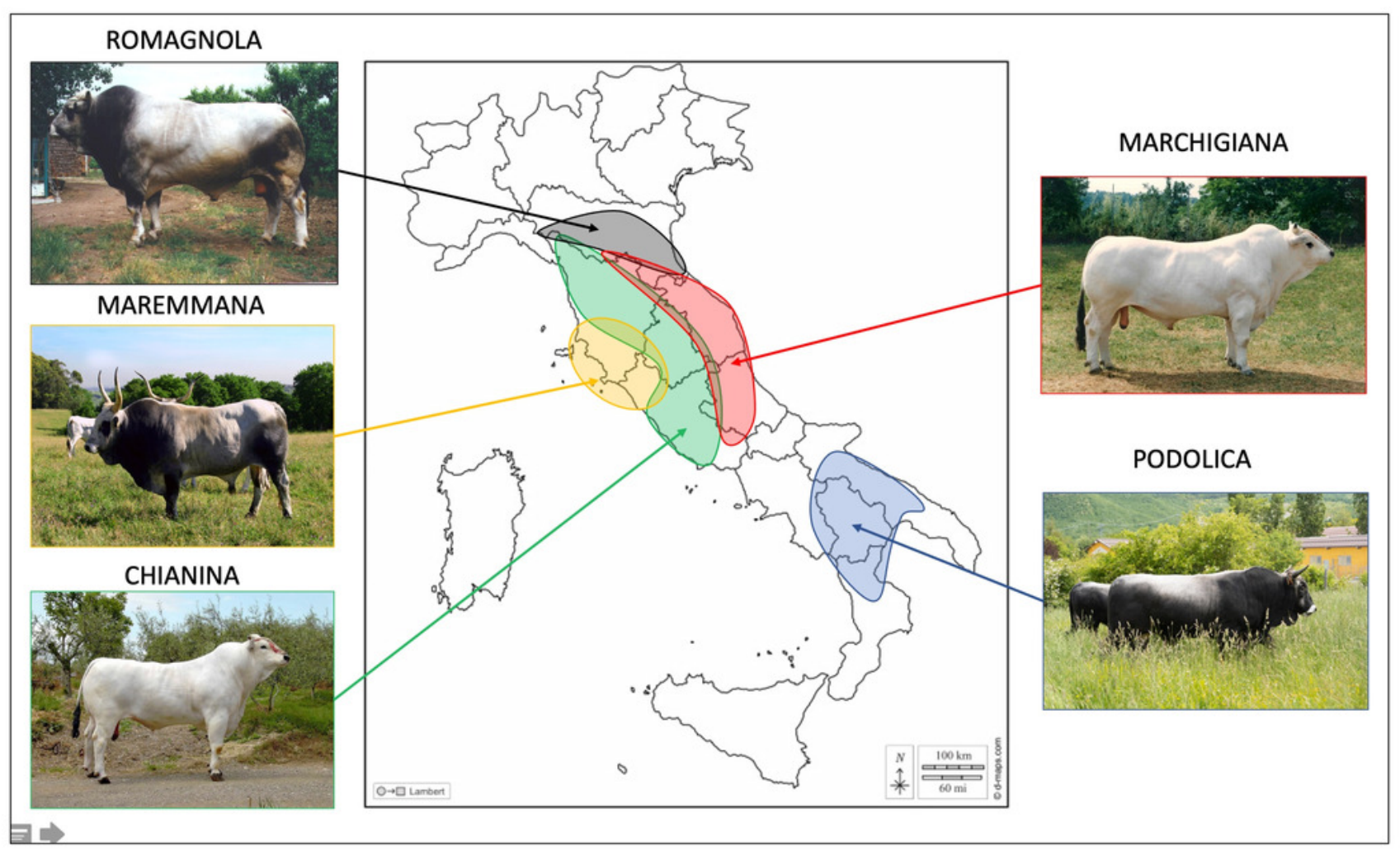




\section{Figure 2}

Molecular $\left(F_{\text {hat } 2}\right)$ and pedigree $\left(F_{\text {ped }}\right)$ inbreeding coefficients and observed heterozygosity of the specialised breeds (Marchigiana, Chianina, and Romagnola) measured in a period of almost 20 years (2002-2019)

Ho: observed heterozygosity; $F_{\text {hat2 }}:$ molecular inbreeding coefficient; $F_{\text {ped: }}$ : pedigree-based inbreeding. The dots represent the mean value and the whiskers are the standard deviation. The base generation, represented as 1985-2002, is composed by animals born between 1985 and 2002 (they have been merged in a single group because data from few bulls were available before 2002).
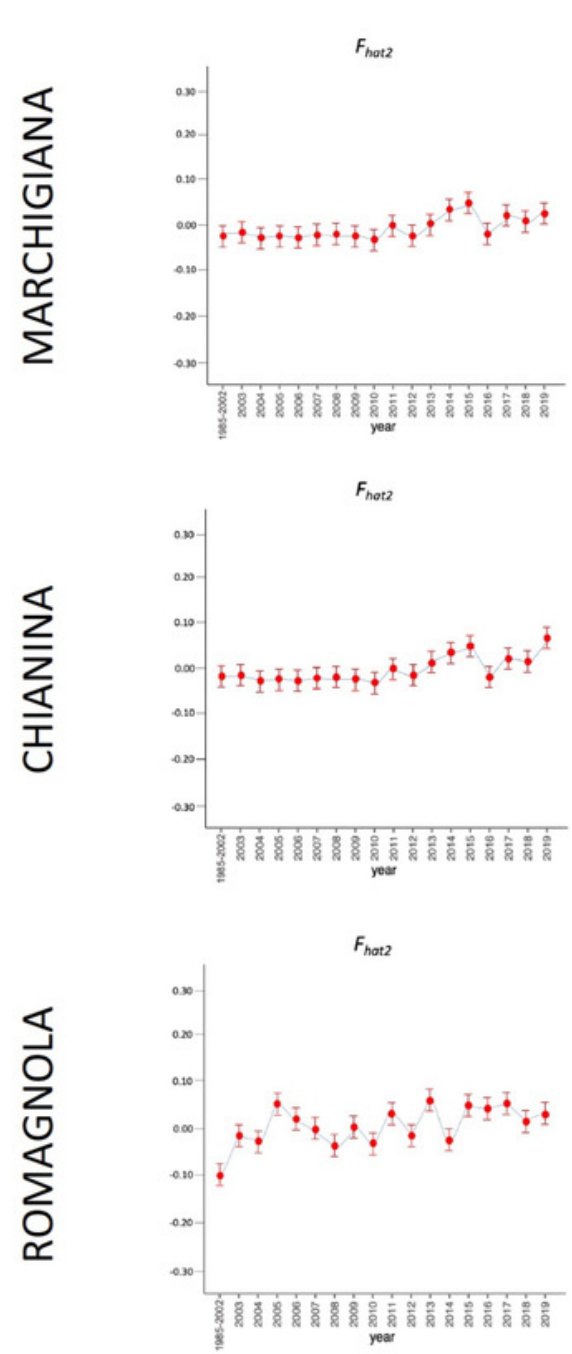
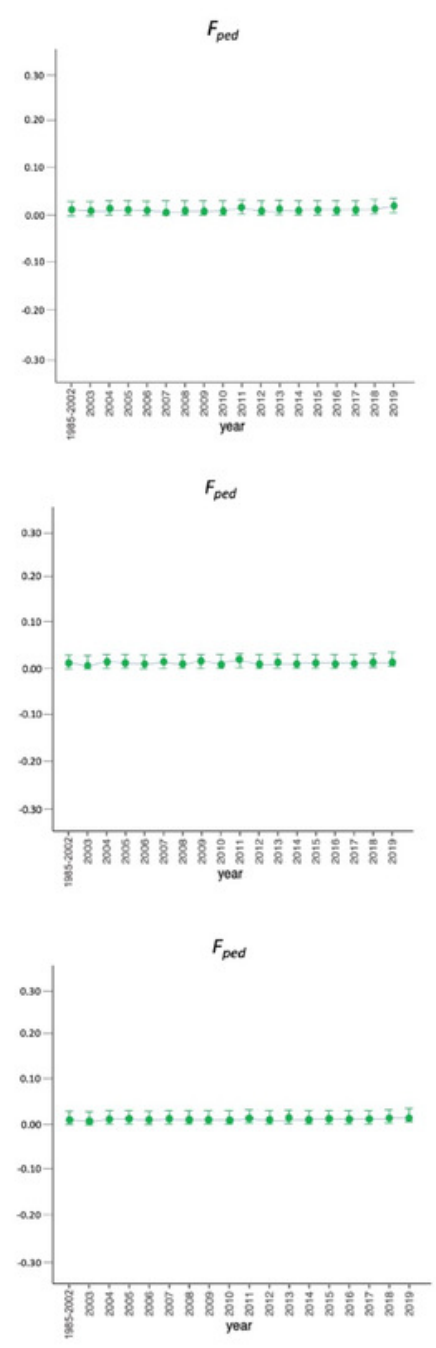

Ho

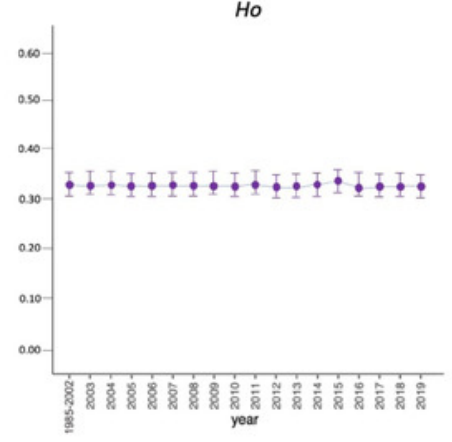

Ho

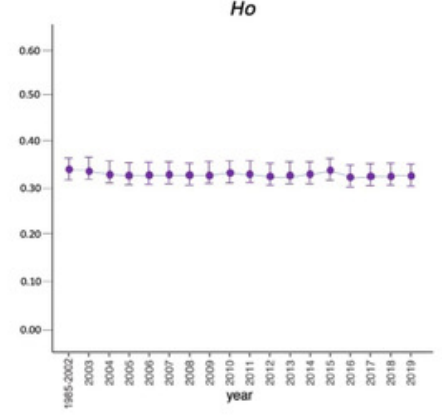

Ho

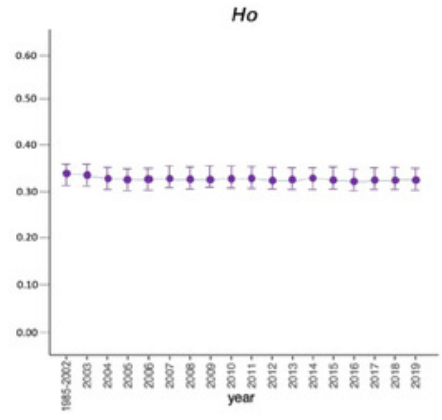




\section{Figure 3}

Molecular $\left(F_{\text {hat } 2}\right)$ and pedigree $\left(F_{\text {ped }}\right)$ inbreeding coefficients and observed heterozygosity of the rustic breeds (Maremmana and Podolica) measured in a period of almost 20 years (2002-2019).

Ho: observed heterozygosity; $F_{\text {hat2 }}:$ molecular inbreeding coefficient; $F_{\text {ped: }}$ : pedigree-based inbreeding. The dots represent the mean value and the whiskers are the standard deviation. The base generation, represented as 1985-2002, is composed by animals born between 1985 and 2002 (they have been merged in a single group because data from few bulls were available before 2002).
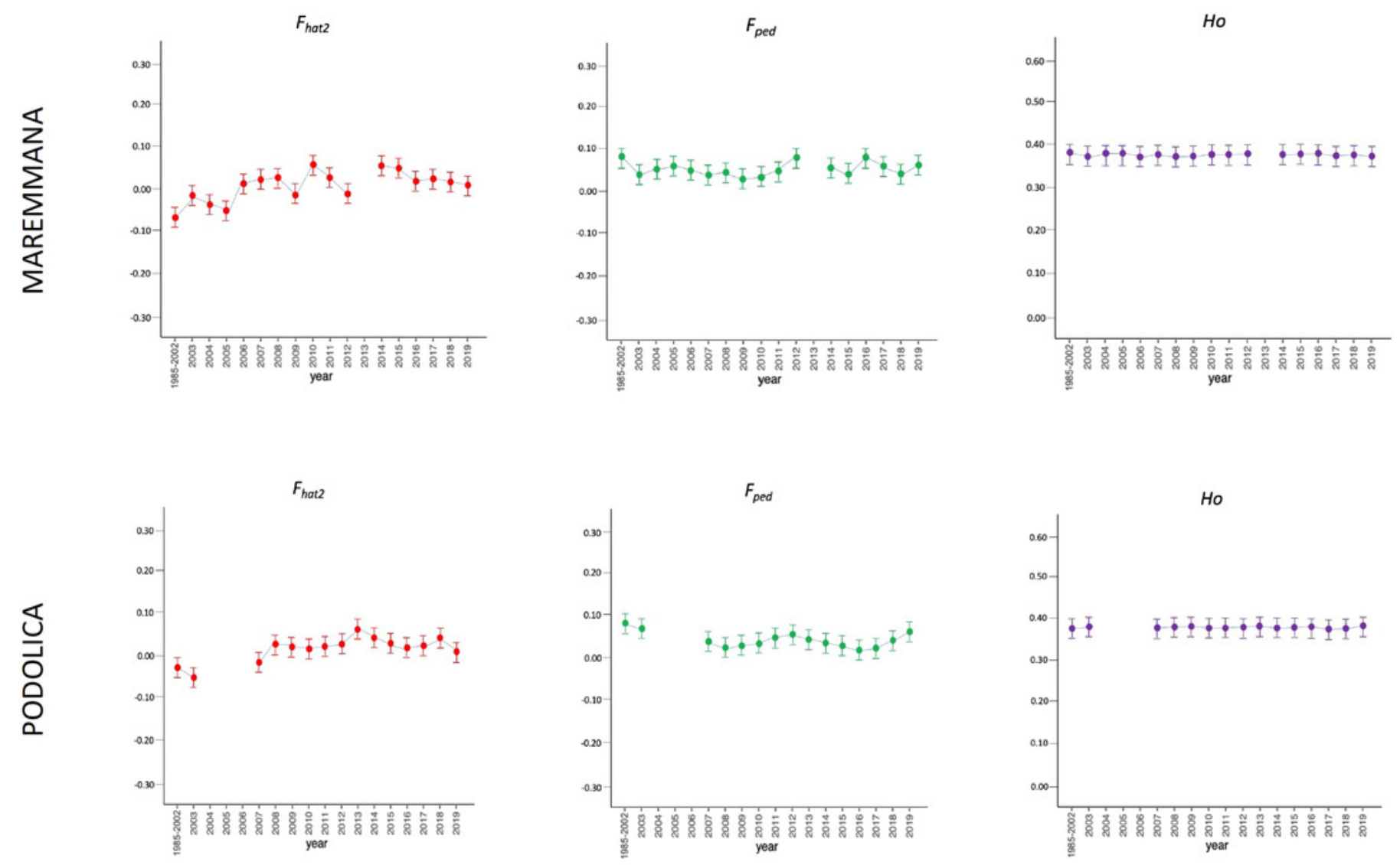
Figure 4

Overall percentual increase of $F_{\text {hat } 2}$ and $F_{\text {ped }}$ for the specialised breeds (Marchigiana, Chianina, and Romagnola).

$F_{\text {hat } 2}:$ molecular inbreeding coefficient; $F_{\text {ped }}$ : pedigree-based inbreeding. The red line represents the regression of the coefficients over time expressed in years. The numbers next to the figure correspond to the overall increase of inbreeding across all analyzed years.

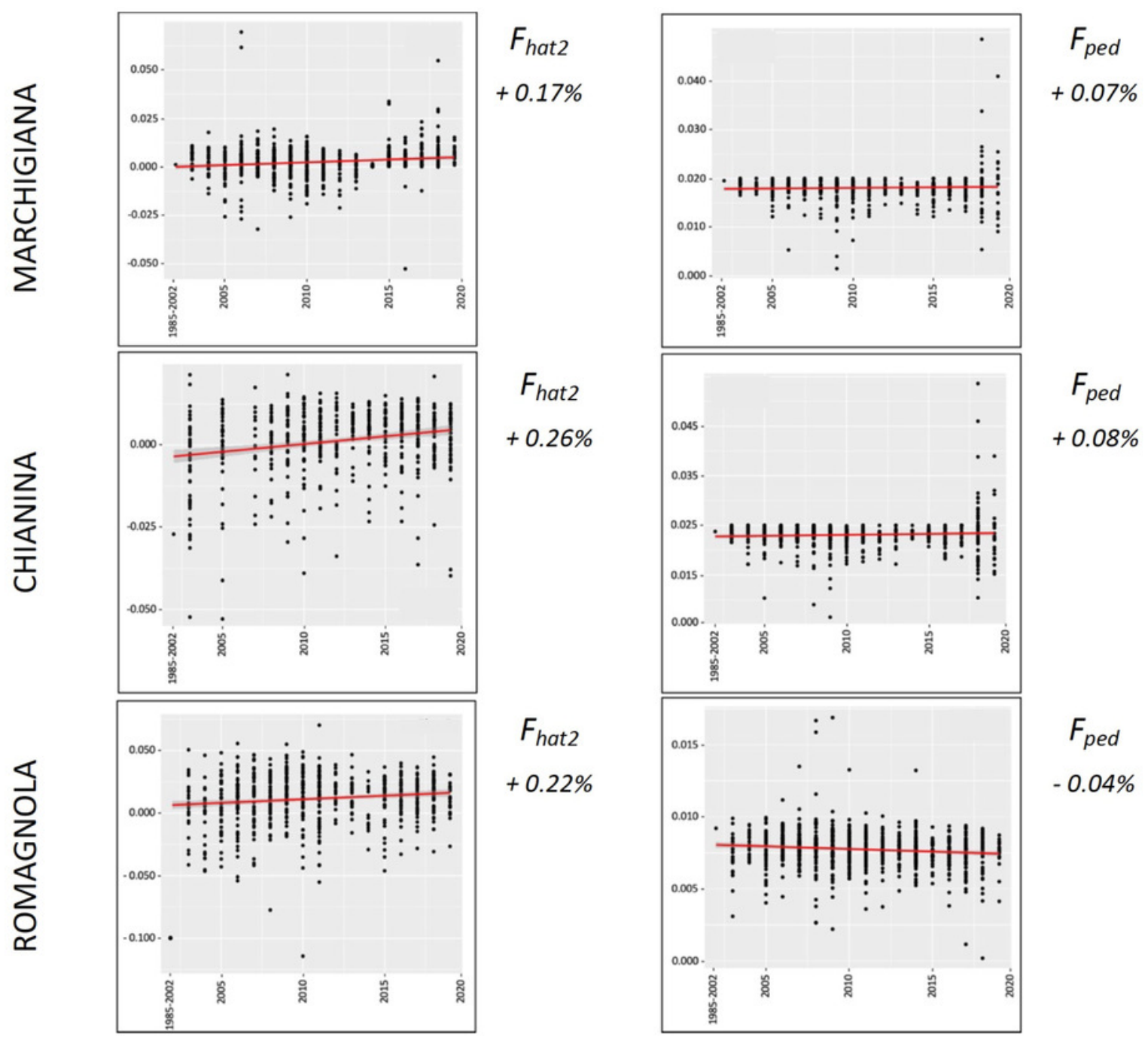


Figure 5

Overall percentual increase of $F_{\text {hat } 2}$ and $F_{p e d}$ for the rustic breeds (Maremmana and Podolica).

$F_{\text {hat } 2}:$ molecular inbreeding coefficient; $F_{\text {ped }}$ : pedigree-based inbreeding. The red line represents the regression of the coefficients over time expressed in years. The numbers next to the figure correspond to the overall increase of inbreeding across all analyzed years.
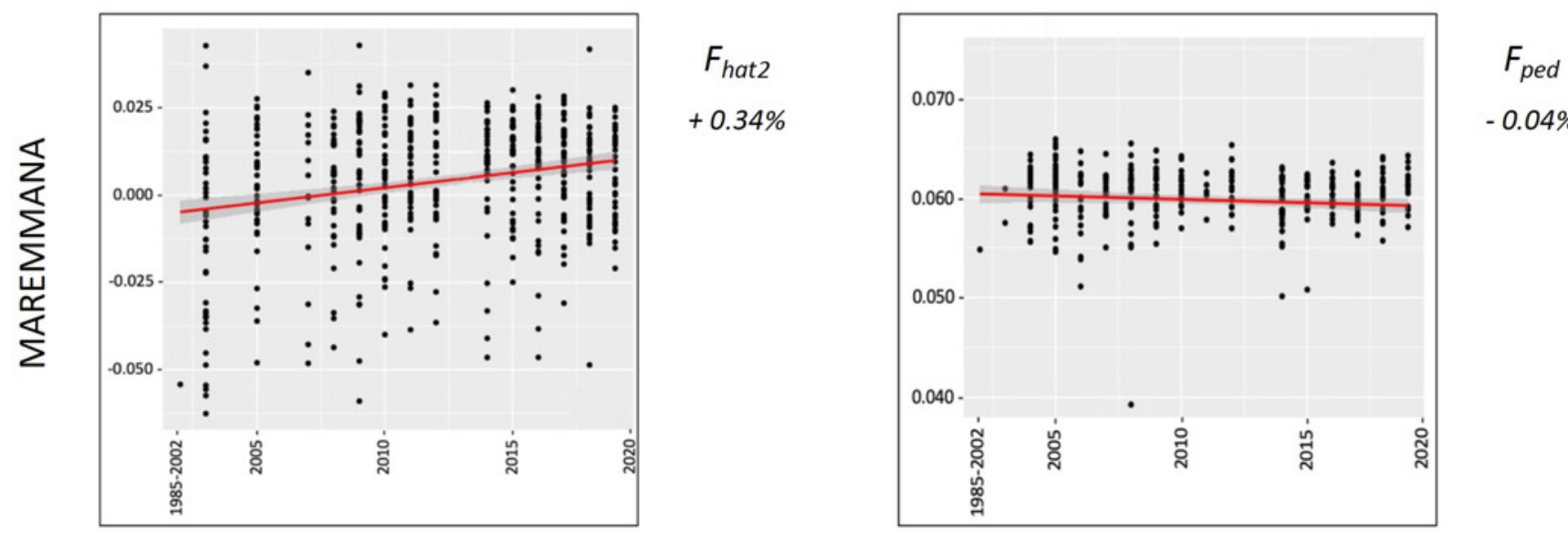

$-0.04 \%$
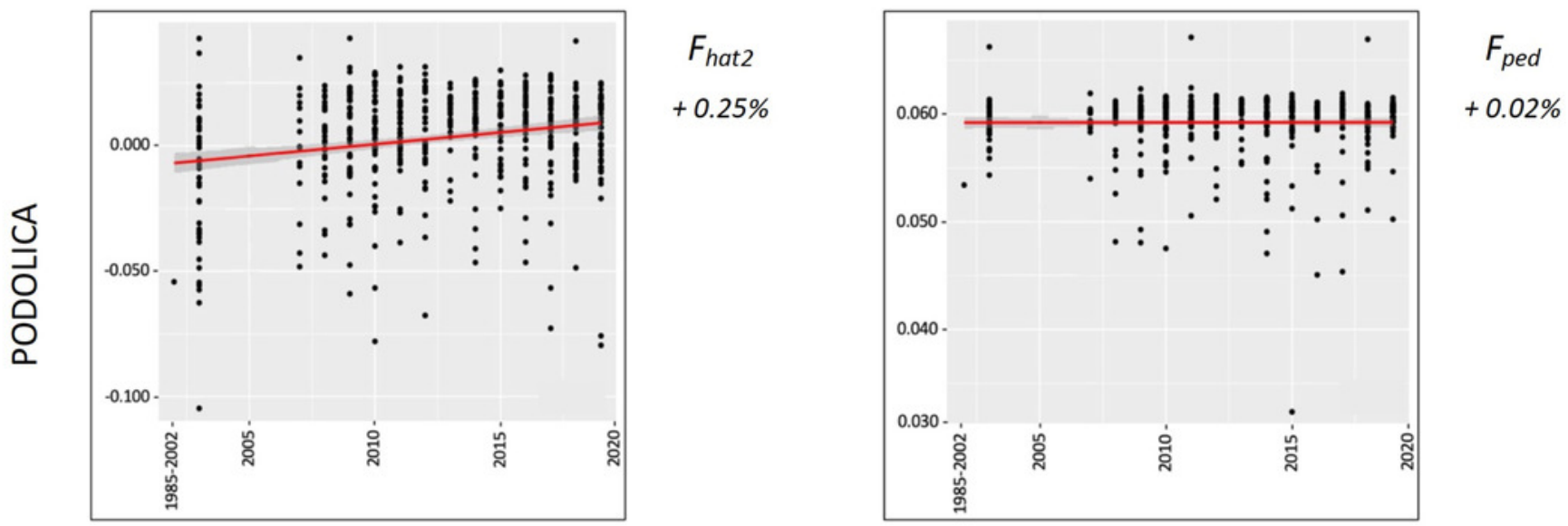
Figure 6

Effective population size $\left(\mathrm{N}_{\mathrm{e}}\right)$ across generation for each Italian beef cattle breed.

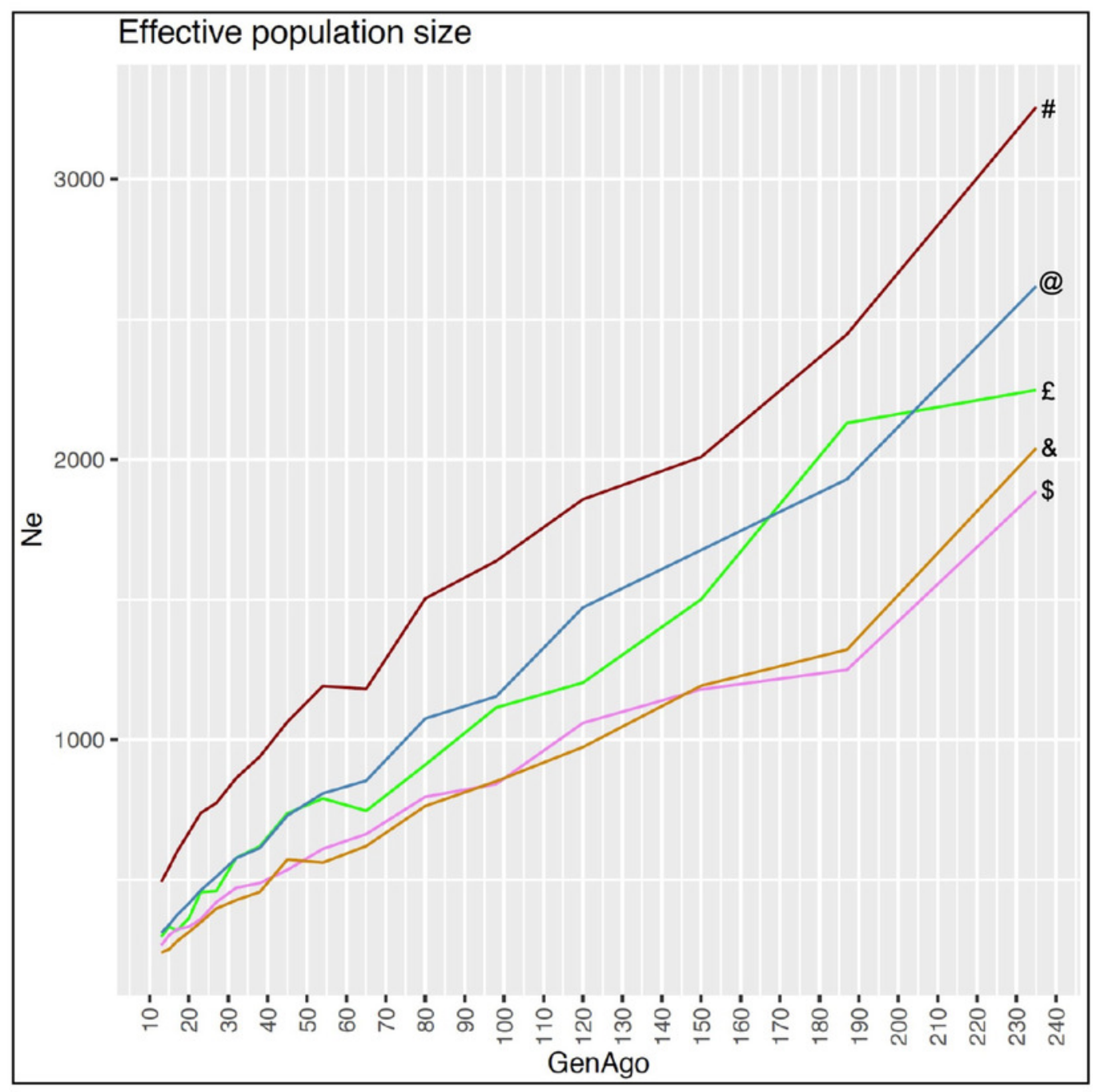

$£$ Marchigiana

\$ Chianina

\& Romagnola

@ Maremmana

\# Podolica 


\section{Table $\mathbf{1}$ (on next page)}

Mean, standard deviation, and range (minimum and maximum values) for expected and observed heterozygosity

${ }^{1} \mathrm{Ho}$ : observed heterozygosity; ${ }^{2} \mathrm{He}$ : expected heterozygosity; ${ }^{3} \mathrm{x} \pm$ sd: mean and standard deviation of $\mathrm{Ho}$ and $\mathrm{He}$; ${ }^{4}$ range: minimum and maximum values of $\mathrm{Ho}$ and $\mathrm{He}$. 
1 Table 1. Mean, standard deviation, and range (minimum and maximum values) for expected

2 and observed heterozygosity.

3

\begin{tabular}{l|cc|cc}
\hline Breed & \multicolumn{2}{|c|}{$\boldsymbol{H o}^{\mathbf{1}}$} & \multicolumn{2}{c}{$\boldsymbol{H e}^{2}$} \\
\hline Marchigiana & $\overline{\boldsymbol{x}} \pm \mathbf{s d}^{\mathbf{3}}$ & range $^{\mathbf{4}}$ & $\overline{\boldsymbol{x}} \pm \mathbf{s d}^{\mathbf{3}}$ & range $^{\mathbf{4}}$ \\
Chianina & $0.350 \pm 0.022$ & $0.349-0.351$ & $0.350 \pm 0.019$ & $0.349-0.352$ \\
Romagnola & $0.361 \pm 0.024$ & $0.359-0.362$ & $0.356 \pm 0.020$ & $0.354-0.359$ \\
Maremmana & $0.383 \pm 0.025$ & $0.380-0.384$ & $0.391 \pm 0.021$ & $0.388-0.392$ \\
Podolica & $0.399 \pm 0.025$ & $0.397-0.401$ & $0.391 \pm 0.021$ & $0.388-0.392$ \\
\hline
\end{tabular}

4

$5 \quad{ }^{1} \mathrm{Ho}$ : observed heterozygosity; ${ }^{2} \mathrm{He}$ : expected heterozygosity; ${ }^{3} \bar{x} \pm \mathrm{sd}$ : mean and standard deviation 6 of $\mathrm{Ho}$ and $\mathrm{He}$; ${ }^{4}$ range: minimum and maximum values of $\mathrm{Ho}$ and $\mathrm{He}$. 


\section{Table 2 (on next page)}

Mean, standard deviation, and range (minimum and maximum values) for different inbreeding coefficients.

${ }^{1} F_{\text {hatr }}$ : molecular inbreeding coefficient; ${ }^{2} F_{\text {ped }}$ : pedigree-based inbreeding; ${ }^{3} \mathrm{x} \pm \mathrm{sd}$ : mean and standard deviation of $F_{\text {hat }}$ and $F_{\text {pedi }}{ }^{4}$ range: minimum and maximum values of $F_{\text {hat } 2}$ and $F_{\text {ped }}$. 
1 Table 2. Mean, standard deviation, and range (minimum and maximum values) for different

2 inbreeding coefficients.

3

\begin{tabular}{l|cc|cc}
\hline Breed & \multicolumn{2}{|c|}{$\boldsymbol{F}_{\text {hat }^{1}}$} & \multicolumn{2}{c}{$\boldsymbol{F}_{\text {ped }}{ }^{2}$} \\
\hline & $\overline{\boldsymbol{x}} \pm \mathbf{s d}^{\mathbf{3}}$ & range $^{\mathbf{3}}$ & $\overline{\boldsymbol{x}} \pm \mathbf{s d}^{\mathbf{3}}$ & range $^{\mathbf{4}}$ \\
Marchigiana & $0.012 \pm 0.005$ & $-0.051-0.071$ & $0.018 \pm 0.002$ & $0.002-0.048$ \\
Chianina & $0.018 \pm 0.005$ & $-0.051-0.023$ & $0.024 \pm 0.003$ & $0.002-0.053$ \\
Romagnola & $0.023 \pm 0.010$ & $-0.121-0.072$ & $0.007 \pm 0.001$ & $0.000-0.016$ \\
Maremmana & $0.014 \pm 0.003$ & $-0.061-0.044$ & $0.062 \pm 0.006$ & $0.039-0.067$ \\
Podolica & $0.025 \pm 0.006$ & $-0.110-0.047$ & $0.061 \pm 0.006$ & $0.032-0.068$ \\
\hline
\end{tabular}

4

$5{ }^{1} F_{\text {hat } 2}$ : molecular inbreeding coefficient; ${ }^{2} F_{\text {ped }}$ : pedigree-based inbreeding; ${ }^{3} \bar{x} \pm \mathrm{sd}$ : mean and

6 standard deviation of $F_{\text {hat } 2}$ and $F_{p e d}$; ${ }^{4}$ range: minimum and maximum values of $F_{\text {hat } 2}$ and $F_{\text {ped }}$. 